\title{
Dantrolene treatment in a patient with uncontrolled hyperthemia after general anesthesia: a case report of suspected malignant hyperthermia - A case report -
}

Received September 28, 2017

Revised October 20, 2017

Accepted October 20, 2017

\section{Corresponding author}

Sung Uk Choi, M.D., Ph.D. Department of Anesthesiology and Pain Medicine, Anam Hospital, Korea University College of Medicine, 73 Inchon-ro, Seongbuk-gu, Seoul 02841, Korea

Tel: 82-2-920-5771

Fax: 82-2-928-2275

E-mail: drchois@korea.ac.kr

\section{ORCID}

http://orcid.org/0000-0003-3609-2253

\section{Kyung Hee Koh, Min Kyung Park, Sung Uk Choi, Hyub Huh, Seung Zhoo Yoon, and Choon Hak Lim}

Department of Anesthesiology and Pain Medicine, Anam Hospital, Korea University College of Medicine, Seoul, Korea

\begin{abstract}
Fever (body temperature above $38^{\circ} \mathrm{C}$ ) is relatively common during the first few days after general anesthesia. Postoperative fever is usually caused by the inflammation induced by surgery and resolves spontaneously; however, it can be a manifestation of a serious complication such as malignant hyperthermia. We report a case of postoperative hyperthermia (body temperature $>40^{\circ} \mathrm{C}$ ) that was refractory to conventional anti-pyretic measures and finally resolved with dantrolene administration.
\end{abstract}

Key Words: Dantrolene, Fever, Malignant hyperthermia, Postoperative period.
Postoperative fever is relatively common after general anesthesia. Most fevers that develop within the first 48 hours after surgery are benign and self-limiting. They are most likely secondary to surgical stress or infections [1]. Besides these, postoperative hyperthermia may arise from several other etiologic factors. Malignant hyperthermia $(\mathrm{MH})$ is a rare and potentially life-threatening form of postoperative hyperthermia.

$\mathrm{MH}$ is a severe hypermetabolic syndrome involving the skeletal muscles. It is usually triggered in susceptible individuals, specifically by volatile anesthetic agents and succinylcholine, although other drugs have also been implicated as potential triggers [2]. In susceptible individuals, abnormal ryanodine receptors in skeletal muscle interfere with the regulation of calcium in the muscle. This causes a buildup of calcium in the skeletal muscle, resulting in an exaggerated metabolic reaction [3]. This hypermetabolism overwhelms the body's capacity to supply oxygen, remove carbon dioxide, and regulate body temperature, eventually leading to circulatory collapse and death if not treated immediately. However, because of the decreased use of succinylcholine and increased use of modern volatile anesthetics (sevoflurane or desflurane), the presentation of $\mathrm{MH}$ is changing from fulminant to insidious [4]. Nevertheless, $\mathrm{MH}$ can still be a lifethreatening disease and can lead to cardiac arrest. Recently, extracorporeal membrane oxygenation has been suggested as a therapeutic option in cases of $\mathrm{MH}$ accompanied by cardiac arrest despite immediate treatment with dantrolene [5].

Dantrolene is the only therapeutic option for MH available currently. Direct or indirect inhibition of the ryanodine receptor is thought to be fundamental to the molecular action of dantrolene in decreasing the intracellular calcium concen-

This is an Open Access article distributed under the terms of the Creative Commons Attribution Non-Commercial License (http://creativecommons.org/licenses/by-nc/4.0) which permits unrestricted non-commercial use, distribution, and reproduction in any medium, provided the original work is properly cited.

Copyright (c) the Korean Society of Anesthesiologists, 2018 
tration [6]. This decrease leads to relaxation of the excessively contracted muscles, reducing lactic acid production and providing relief from hyperthermia.

We report a case of uncontrolled high fever after general anesthesia that responded to dantrolene administration.

\section{CASE REPORT}

A 77-year-old Korean woman (height $150 \mathrm{~cm}$, weight $36 \mathrm{~kg}$ ) presented to the emergency department with right hip joint pain, was diagnosed with right intertrochanteric fracture of femur, and underwent emergency closed reduction and intramedullary nail implantation. The patient had a medical history of hypertension, unstable angina, Parkinson's disease, and dementia; she had no previous history of surgery or general anesthesia. Except for mild hyperthermia and proteinuria, the preoperative evaluation results were within normal range. Body temperature measured with an ear thermometer (ThermoScan, Braun, Switzerland) was $37.4^{\circ} \mathrm{C}$. After premedication with $0.2 \mathrm{mg}$ of glycopyrrolate, the patient underwent induction of general anesthesia with $70 \mathrm{mg}$ of propofol and $40 \mathrm{mg}$ of rocuronium intravenously, followed by placement of an endotracheal tube. General anesthesia was maintained with $2.0-2.5 \mathrm{vol} \%$ of sevoflurane and $0.05-0.10 \mu \mathrm{g} / \mathrm{kg} / \mathrm{min}$ of remifentanil.

The intraoperative course was uneventful and patient's core temperature measured with an esophageal stethoscope (400 Series, DeRoyal, USA) was within $37.3^{\circ} \mathrm{C}-37.4^{\circ} \mathrm{C}$. No active warming or cooling was done during surgery. The total anesthesia time was 70 minutes, and the patient was extubated after administration of $50 \mu \mathrm{g}$ of fentanyl. The patient maintained spontaneous ventilation well and was admitted to the post-anesthesia care unit and observed for 60 minutes. The patient was afebrile and her vital signs remained stable, with a heart rate ranging between $75-80$ beats $/ \mathrm{min}$. She was discharged to the ward in a stable condition. However, 5 hours later, her body temperature had increased to $38.1^{\circ} \mathrm{C}$ and did not reduce in response to antipyretic therapy and ice-bag application; 30 hours later, she became delirious and showed disorientation in terms of time, place, and person. Her condition was assumed to be related to her pre-existing dementia. Her body temperature increased steadily to $39^{\circ} \mathrm{C}$ and $40^{\circ} \mathrm{C}$ on the second and third postoperative days (POD), respectively, and her mental status worsened and progressed to stupor.
On the third postoperative day, her urine was brown in color, but urinalysis demonstrated only mild hematuria (30-59 erythrocytes/High Power Field) and proteinuria (+1). The urine test for myoglobin (a sign of $\mathrm{MH}$ ), was negative. Until then, we were thinking about the possibility of urinary tract infection, pneumonia, or less likely surgical site infection.

As the fever was unresponsive to therapy including continuous administration of antipyretic (propacetamol) and antibiotics (cefazedone and levofloxacin), a late $\mathrm{MH}$ reaction was suspected, and the patient was transferred to the intensive care unit (ICU) on the fifth POD. No infectious focus was identified and neurologic diseases like neuroleptic syndrome and serotonergic syndrome were ruled out upon consultation with a neurologist. A clinical diagnosis of late type of $\mathrm{MH}$ was made, and cooling treatment including dantrolene was initiated. Three and a half hours after the initial intravenous dose of $80 \mathrm{mg}$ of dantrolene, her body temperature decreased from $38.4^{\circ} \mathrm{C}$ to $36.3^{\circ} \mathrm{C}$. An additional dose of $36 \mathrm{mg}$ of dantrolene ( 1 $\mathrm{mg} / \mathrm{kg}$ ) was administered six hours after the first dose.

Four hours after the second dose of dantrolene, the patient's body temperature remained within the normal range, but she began to show signs of respiratory failure. Arterial blood gases revealed a $\mathrm{pH}$ of $6.895, \mathrm{PaO}_{2}$ of $78.2 \mathrm{mmHg}$, $\mathrm{PaCO}_{2}$ of $126.9 \mathrm{mmHg}, \mathrm{HCO}_{3}^{-} 24.8 \mathrm{mEq} / \mathrm{L}$, Base excess of -8.4 , and oxygen saturation of $80.5 \%$. Intubation and mechanical ventilation support was initiated. During conservative care in the ICU, she presented with elevated serum myoglobin and creatine phosphokinase (CPK) levels and prerenal acute kidney injury (AKI) on the sixth POD. With continued supportive treatment, her condition stabilized and extubation was done on the 13th POD. Subsequently, she was transferred to general ward on the 18th POD. After two months of rehabilitation, the patient was discharged without any complications. The patient was advised to avoid sevoflurane exposure in any future anesthetic procedure.

\section{DISCUSSION}

MH can lead to drastic deterioration in the patient's condition within a short time after onset; thus, it is a condition that every anesthesiologist should aware of. However, it is very difficult to predict which patient could be at higher risk for $\mathrm{MH}$ before the operation; the only effective therapy is dantrolene, which is rare and not readily available in every hospital. Thus, 
a high index of suspicion and early diagnosis and treatment are important in improving the outcome of this syndrome.

The earliest clinical signs of $\mathrm{MH}$ may include an increase in the end-tidal carbon dioxide concentration, unexplained tachycardia, and muscle rigidity [2]. Despite the name, fever is often a late sign, although it may appear early in severe cases. Later signs include fever, tachypnea, cyanosis, myoglobinuria, hyperkalemia, and multiple organ failure. In the present case, the symptoms listed above were not observed; however, hyperthermia and elevated serum myoglobin and CPK levels were observed late in the course of the disease; no myoglobinuria or hyperkalemia was observed.

The North American Malignant Hyperthermia Registry (NAMHR) reports that postoperative $\mathrm{MH}$ is a very rare $(<2 \%$ of all cases) and is generally observed within one hour after anesthesia [7]. None of these cases had hyperthermia as an initial presenting sign. NAMHR suggested that initial postoperative hyperthermia, without signs of hypermetabolism, is unlikely to be $\mathrm{MH}$ [7]. However, a case of postoperative $\mathrm{MH}$ in a child, who died from unavailability of dantrolene, was reported recently. The only symptoms in that case were tachypnea and hyperthermia [8]. In our case, uncontrolled postoperative hyperthermia was an initial sign.

The gold standard for the diagnosis of MH susceptibility is the caffeine-halothane contracture test, but DNA analysis, requiring only a blood sample, could be an alternative to this invasive test [2]. However, as this test is not widely available, the diagnosis of $\mathrm{MH}$ has to be made on the basis of clinical presentation in most cases. The genotype of the patient reported here has not been analyzed yet because this facility is not available in any institution in South Korea at present, so we cannot definitely diagnose the patient with $\mathrm{MH}$. The diagnosis of $\mathrm{MH}$ in this case was based on clinical symptoms and the response to dantrolene. A 1994 International Consensus Conference led to the formulation of a set of diagnostic criteria and a clinical grading scale (CGS) for MH susceptibility [9]. The higher the score, the more likely was a reaction to be $\mathrm{MH}$. According to CGS, the clinical features of the present case scored 43 which suggests it was very likely case of $\mathrm{MH}$.

In the current situation, it is suspected that the malignant hyperthermia was caused by the sevoflraune. However, $\mathrm{MH}$ onset time was faster during sevoflurane (median time, 45 minutes) than isoflurane (median time, 135 minutes) or desflurane (median time, 113.5 minutes) anesthesia [10]. No causative anesthetic drugs were reported in $7 \mathrm{MH}$ cases [10]. For now, it is wise to advise the patient to avoid sevoflurane exposure in any future anesthetic procedure.

Currently, dantrolene is the only treatment available for $\mathrm{MH}$. Because $\mathrm{MH}$, which presents with nonspecific signs, can be life-threatening if treatment is delayed, dantrolene should be administered as soon as $\mathrm{MH}$ is suspected. However, dantrolene has its own adverse effects, the more frequent of which are muscle weakness (21.7\%), phlebitis (9\%), gastrointestinal discomfort (4.1\%), and respiratory failure (3.8\%) [11]. Additionally, despite dantrolene treatment, 25\% of patients will develop recurrence of $\mathrm{MH}$. Therefore, patients experiencing $\mathrm{MH}$ should receive dantrolene and be monitored closely for 48-72 hours [2]. In our case, the patient's body temperature decreased to the normal range after dantrolene administration, but respiratory failure, elevated serum myoglobin and CPK levels, and AKI were observed. These side effects could be due to dantrolene administration, but it is not possible to exclude the recrudescence or progression of $\mathrm{MH}$.

Uncontrolled hyperthermia is independently associated with increased morbidity and mortality. Hyperthermia itself may cause rhabdomyolysis, disseminated intravascular coagulation, and multi-organ failure. It has been noted that dantrolene may be effective in treating hyperthermia from many causes unrelated to MH caused by anesthesia [12]. On the basis of the similarity between a variety of drug-induced hyperthermic syndromes and $\mathrm{MH}$, dantrolene has been used to effectively treat several syndromes, such as the neuroleptic malignant syndrome, 3,4-methylenedioxy-methamphetamine toxicity, and hyperthermia related to the new onset of juvenile diabetes in adolescents [13-15].

This case was not a typical example of $\mathrm{MH}$, but dantrolene administration caused immediate recovery from symptoms and aided patient recovery. The introduction of modern volatile anesthetics, which research indicates are less potent as triggering agents for $\mathrm{MH}$, and the recommended limitations of succinylcholine use, point toward a considerable decline in fulminant $\mathrm{MH}$ cases. However, $\mathrm{MH}$ is still an important anesthetic complication. Every anesthesiologist should recognize that late-onset fulminant $\mathrm{MH}$ is a possibility, and atypical types of $\mathrm{MH}$ can present at any time. Rapid initiation of definitive therapy is crucial to avoid major complications and a possibly lethal outcome. Dantrolene must be readily available wherever $\mathrm{MH}$-triggering agents are used for anes- 
thesia.

In conclusion, this case reminds us that a high index of suspicion and early diagnosis and treatment could improve survival and prognosis in patients with symptoms indicative of $\mathrm{MH}$.

\section{REFERENCES}

1. Pile JC. Evaluating postoperative fever: a focused approach. Cleve Clin J Med 2006; 73 Suppl 1: S62-6.

2. Rosenberg H, Davis M, James D, Pollock N, Stowell K. Malignant hyperthermia. Orphanet J Rare Dis 2007; 2: 21.

3. MacLennan DH, Duff C, Zorzato F, Fujii J, Phillips M, Korneluk RG, et al. Ryanodine receptor gene is a candidate for predisposition to malignant hyperthermia. Nature 1990; 343: 559-61.

4. Heytens L, Forget P, Scholtès JL, Veyckemans F. The changing face of malignant hyperthermia: less fulminant, more insidious. Anaesth Intensive Care 2015; 43: 506-11.

5. Huh H, Jung JS, Park SJ, Park MK, Lim CH, Yoon SZ. Successful early application of extracorporeal membrane oxygenation to support cardiopulmonary resuscitation for a patient suffering from severe malignant hyperthermia and cardiac arrest: a case report. Korean J Anesthesiol 2017; 70: 345-9.

6. Krause T, Gerbershagen MU, Fiege M, Weisshorn R, Wappler F. Dantrolene--a review of its pharmacology, therapeutic use and new developments. Anaesthesia 2004; 59: 364-73.

7. Litman RS, Flood CD, Kaplan RF, Kim YL, Tobin JR. Postoperative malignant hyperthermia: an analysis of cases from the North
American Malignant Hyperthermia Registry. Anesthesiology 2008; 109: 825-9.

8. Sinha AK, Kumari P, Vaghela MM, Sinha C, Kumar B. Postoperative malignant hyperthermia- a medical emergency: a case report and review of literature. J Clin Diagn Res 2017; 11: PD01-2.

9. Larach MG, Localio AR, Allen GC, Denborough MA, Ellis FR, Gronert GA, et al. A clinical grading scale to predict malignant hyperthermia susceptibility. Anesthesiology 1994; 80: 771-9.

10. Visoiu M, Young MC, Wieland K, Brandom BW. Anesthetic drugs and onset of malignant hyperthermia. Anesth Analg 2014; 118: 388-96.

11. Brandom BW, Larach MG, Chen MS, Young MC. Complications associated with the administration of dantrolene 1987 to 2006: a report from the North American Malignant Hyperthermia Registry of the Malignant Hyperthermia Association of the United States. Anesth Analg 2011; 112: 1115-23.

12. Inada H, Jinno S, Kohase H, Fukayama H, Umino M. Postoperative hyperthermia of unknown origin treated with dantrolene sodium. Anesth Prog 2005; 52: 21-3.

13. Pileggi DJ, Cook AM. Neuroleptic malignant syndrome. Ann Pharmacother 2016; 50: 973-81.

14. Grunau BE, Wiens MO, Brubacher JR. Dantrolene in the treatment of MDMA-related hyperpyrexia: a systematic review. CJEM 2010; 12: 435-42.

15. Hollander AS, Olney RC, Blackett PR, Marshall BA. Fatal malignant hyperthermia-like syndrome with rhabdomyolysis complicating the presentation of diabetes mellitus in adolescent males. Pediatrics 2003; 111: 1447-52. 